\title{
Modeling individual-tree growth in stands under forest conversion in East Germany
}

\author{
J. Schröder · H. Röhle $\cdot$ D. Gerold $\cdot$ K. Münder
}

Published online: 5 April 2007

(C) Springer-Verlag 2007

\section{Erratum to: Eur J Forest Res DOI 10.1007/s10342-006-0167-x}

Unfortunately two errors were introduced in the corrections process:

In Table 3 "'Morality", should read "Mortality".

In Eqs. 6 and 7 a minus sign is missing. Here are the correct equations together with the text.

Modeling mortality

The alternative sub-model introduced into the Saxon BWINPro version estimates the individual mortality of a tree in a three-step algorithm. It was calibrated for spruce, pine, and beech (Röhle et al. 2004. A logistic function computing a vitality-indicating $F$-value ( 0 for death, 1 for survival) is the first part of the model:
$F=\left[1+\exp \left(-\left(a_{0}+a_{1} \cdot d+a_{2} \cdot(i g / d)+a_{3} \cdot(h / d)\right)\right)\right]^{-1}$

where $d=\mathrm{dbh}, h / d=$ height-to-dbh ratio, $i g=$ basal area increment of a tree during the previous five-year period. Parameters $a_{0}-a_{3}$ were obtained by applying the maximum likelihood method to weighted samples with equal numbers of dead and live trees from a wide array of frequently measured plots in Saxony and adjacent regions. In the second step, species-dependent inverse-exponential functions assign a specific value of mortality likelihood $(M L)$ to the individual $F$-value of a tree:

$M L=a_{0} \cdot\left[\exp \left(a_{1} \cdot F^{a_{2}}\right)\right]^{-1}$

The online version of the original article can be found at http://dx.doi.org/10.1007/s10342-006-0167-x.

J. Schröder ( $\square)$

Eberswalde Forest Research Station,

FB 2, Alfred-Moeller-Straße 1,

16225 Eberswalde, Germany

e-mail: schroeder.jens@gmx.com

H. Röhle · D. Gerold · K. Münder

Dresden University of Technology,

Chair of Forest Growth Science,

Pienner Straße 8, 01737 Tharandt, Germany 